\title{
Boğmaca/Boğmaca Benzeri Hastalık Nedeniyle Hastaneye Yatırılan 4 Aydan Küçük Bebeklerin Klinik Özellikleri
}

\author{
Clinical Features of 1-4 Months Old Infants Hospitalized with \\ Pertussis/Pertussis-Like Disease
}

Fatma Zehra ÖZTEK ÇELEBI, Melahat Melek OĞUZ, Saliha ŞENEL

Sağlık Bilimleri Üniversitesi, Dr. Sami Ulus Kadın-Doğum, Çocuk Sağlığı ve Hastalıkları SUAM, Ankara, Türkiye

öz

Amaç: Boğmaca ciddi bir halk sağlığı sorunudur ve 5 yaş altındaki aşı ile önlenebilir ölümlerin önemli bir nedenidir. Bu çalışmada boğmaca/boğmaca benzeri hastalık ön tanısı ile yatıılarak izlenmiş hastaların klinik verilerinin sunulması amaçlanmıştır.

Gereç ve Yöntemler: Ocak 2018-Eylül 2018 tarihleri arasında boğmaca, boğmaca benzeri hastalık tanısıyla yatırılan, yașı 4 aydan küçük olan hastalar retrospektif olarak incelendi.

Bulgular: Toplam 97 hasta (51 erkek, 46 kı) boğmaca/boğmaca benzeri hastalık tanısı ile izlendi. Hastaların ortanca yaşı 2 (min-maks 0.97-3.90) aydı. Olguların hepsinde başvuru sırasında nöbetler halinde gelen boğulur tarzda öksürük, 32 olguda (\%33) akciğerde ral ve/veya ronkus, 5 olguda apne, 36 olguda takipne vardı. Otuz bir hastadan (\%32) boğmaca için nazofaringeal sürüntü örneği gönderildi. Gönderilen 31 örnekten 12'sinde polimeraz zincir reaksiyonu (PZR) ile B. pertussis pozitif olarak saptandı (\%39). Yatış süresi ve hastaların yașı açısından boğmaca PZR pozitif, boğmaca PZR negatif ve tetkik alınmamış grup arasında anlamlı fark yoktu. Boğmaca PZR pozitif grubunun beyaz küresi ve lenfosit sayısı diğer iki gruba göre anlamlı olarak daha yüksekti. Hastaların 2 tanesi ilk yatış günlerinden sonra solunum sıkıntısı nedeniyle yoğun bakıma devredildi. İkisi de mekanik ventilatör desteği aldı ve şifa ile taburcu edildi.

Sonuç: Boğmaca enfeksiyonu erken bebeklik döneminde önemli morbidite ve mortaliteye neden olmaktadır. Bu bebekleri korumak için uygun stratejiler geliştirilmelidir.

Anahtar Sözcükler: Bordetella pertussis, Morbidite, Mortalite, Öksürük

\begin{abstract}
Objective: Pertussis is a serious public health problem and a major cause of vaccine-preventable deaths under 5 years of age. The aim of this study is to present the clinical data of the patients who were hospitalized with the diagnosis of pertussis/pertussis-like disease.

Material and Methods: Hospitalized 1-4 months old infants diagnosed with pertussis/ pertussis-like disease from January 2018 to September 2018 at I were assessed retrospectively.

Results: A total of 97 patients (51 males, 46 females) were diagnosed with pertussis/pertussis-like disease. Median age of the patients was 2 months (min-max 0.97-3.90). There was spasmodic cough in all cases. Thirty-two (33\%) cases had abnormal lung auscultation sounds (rales and/or rhonchi), 5 cases had apnea and 36 cases had tachypnea. Nasopharyngeal smears for pertussis were taken from 31 patients (32\%). Twelve from 31 nasopharyngeal smears (39\%) were positive for $B$. pertussis using polymerase chain reaction (PCR). There was no significant difference between pertussis PCR positive group, pertussis PCR negative group and unexamined group in terms of hospital stay and age of patients. Total leucocyte and lymphocyte count in pertussis PCR positive group were significantly higher than in other
\end{abstract}

(1)

ÖZTEK ÇELEBI FZ: 0000-0002-2203-5904 OĞUZ MM : : :0000-0002-4196-4469 SENEL S : :0000-0001-7203-5884
Çıkar Çatıșması / Conflict of Interest: Tüm yazarlar adına, sorumlu yazar çıkar çatıșması olmadığını belirtir.

Etik Kurul Onayı / Ethics Committee Approval: Bu çalıșmada ulusal ve uluslararası etik kurallara uyulmuştur. Çalışma için Sağlık Bilimleri Üniversitesi, Ankara Dr. Sami Ulus Kadın-Doğum Çocuk Sağlığı ve Hastalıkları Eğitim ve Araștırma Hastanesi, Tıpta Uzmanlık Eğitimi Kurulu (TUEK)'ndan (Karar No: 2019-1217) izin alındı. Kayıt sırasında veliler tarafından araștırmaya katılım için bilgilendirilmiș bir onay imzalanmıștır.

Yazarların katkısı / Contribution of the Authors: ÖZTEK ÇELEBi FZ: Araștımanın hipotezini oluşturmada, yöntemini belirlemede, verilerin toplanmasında, analiz edilmesinde, kaynak taramasında ve çalıșmanın yazımasında katkı sağlamıştı, OĞUZ $\mathbf{M M}$ : Verilerin toplanmasındada, yorumlamasında, çalıșmanın yazılmasında ve eleștirisel incelemesinde katkı sağlamıștır, ŞENEL S: Araștırmanın hipotezini olușturmasında ve planlanmasında, yönteminin belirlenmesinde, çalıșmanın yazılmasında ve eleștirisel incelemesinde katkı sağlamıștır.

Atıf yazım şekli / How to cite : Öztek Çelebi FZ, Oğuz MM, Şenel S. Boğmaca/Boğmaca Benzeri Hastalık Nedeniyle Hastaneye Yatırlan 4 Aydan Küçük Bebeklerin Klinik Özellikleri. Turkish J Pediatr Dis 2021; 15: 48-51. 
two groups. Two patients were referred to the intensive care unit due to respiratory distress after their first day of hospitalization. Both received mechanical ventilator support and were discharged with cure.

Conclusion: Pertussis infection causes significant morbidity and mortality in early infancy. Appropriate strategies should be developed to protect these babies.

Key Words: Bordetella pertussis, Morbidity, Mortality, Cough

\section{Giriş}

Boğmaca Bordetella pertussis (B. pertussis)'in etken olduğu oldukça bulaşıcı bir solunum yolu enfeksiyonudur. Hastalık inatçı öksürük nöbetleri ile karakterizedir. Dünya Sağlık örgütü (DSÖ)'ne üye 194 ülkenin 129'unda boğmaca aşılanma hızı \%90'ın üzerinde olmasına rağmen, boğmaca günümüzde önemli bir sağllk sorunudur ve beş yaş altındaki çocuklarda aşı ile önlenebilir ölümlerin beșinci nedenidir $(1,2)$. Enfeksiyon her yaştan bireyi etkilemekle birlikte özellikle erken bebeklik döneminde önemli mortalite ve morbidite sebeplerindendir (3, 4). ABD'de 2010 ylındaki boğmaca epidemisinde boğmaca vakalarının çoğunun altı aydan küçük çocuklar olduğu, hastaneye yatırıma ve ölüm oranlarının üç aydan küçük bebeklerde daha yüksek olduğu bildirilmiştir (5).

Bu çalışmada boğmaca/boğmaca benzeri hastalık ön tanısı ile yatırılarak izlenmiş olan hastaların klinik özelliklerinin değerlendirilmesi amaçlandı.

\section{GEREÇ ve YÖNTEMLER}

Ocak 2018-Eylül 2018 tarihleri arasında boğmaca/boğmaca benzeri hastalık tanısıyla yatıılan, yaşları 4 aydan küçük tüm hastalar çalışmaya dâhil edildi. Boğmaca tanısı DSÖ'nün kriterlerine göre konuldu (6).

\section{Bu tanımlamaya göre;}

Klinik tanımlama; bir hekim tarafından boğmaca tanısı konulan vakalar ya da en az iki hafta süren öksürüğe aşağıdaki semptomlardan en az birinin eşlik etmesidir; 1) Paroksismal öksürük, 2) Inspiratuar stridor, 3) Öksürük sonrası kusma

Laboratuvar tanımlama: $B$. pertussis'in kültür ile izole edilmesi, polimeraz zincir reaksiyonu (PZR) ile saptanması veya seroloji pozitifliği.

Klinik vaka: Klinik tanımlamaya uyan fakat laboratuvar testleri negatif olgular.

Laboratuvar ile kanıtlanmış vaka: Klinik tanımlamaya uyan ve laboratuvar testlerinden birisi pozitif saptanmış olgular.

Bu tanımlamalara uyan 97 hastanın yaşı, cinsiyeti, klinik bulguları, hastanede yatıs süreleri, laboratuvar ve nazofaringeal sürüntü örneği sonuçları (B. pertussis için PZR ve kültür), solunum sıkıntısı ve mekanik ventilatör desteği alma durumları retrospektif olarak kaydedildi.

Çalışma için Sağlık Bilimleri Üniversitesi, Ankara Dr. Sami Ulus Kadın-Doğum Çocuk Sağlığı ve Hastalıkları Eğitim ve Araştırma
Hastanesi, Tıpta Uzmanlık Eğitimi Kurulu (TUEK)'ndan (Karar No: 2019-1217) izin alındı.

Verilerin istatiksel analizi SPSS 15.0 programında yapıldı. Nominal değişkenler için frekans ve yüzde değerleri, sürekli değişkenler için ise ortanca, minimum, maksimum değerleri verildi. Gruplar arasında ortancalar yönünden farkın önemliliği Kruskal Wallis testi ile değerlendirildi. Nominal değişkenler Pearson Ki- Kare veya Fisher'in tam sonuçlu olaslllk testi ile karşılaştııldı. p<0.05 değerleri istatistiksel olarak anlamlı kabul edildi.

\section{BULGULAR}

Toplam 97 hasta (51 erkek, 46 kı) boğmaca/boğmaca benzeri hastalık tanısı ile izlendi. Hastaların demografik ve laboratuvar bulguları Tablo l'de gösterilmektedir. Başvuru sırasında olguların tamamında $(n=97)$ nöbetler halinde gelen boğulur tarzda öksürük, 32 olguda (\%33) akciğer muayenesinde ral ve/veya ronkus, 5 olguda apne, 36 olguda takipne saptandı. Otuz bir (\%32) hastadan boğmaca için nazofaringeal sürüntü örneği, 17 hastadan da eş zamanlı olarak solunum yolu PZR testi gönderilmişti. Gönderilen 31 nazofaringeal örnekten 12'sinde (\%39) PZR ile B. pertussis pozitifliği, 7 hastada ise B. pertussis için hem kültür hem de PZR testi pozitifliği saptandı. On yedi solunum yolu PZR testinin 6'sında viral etkene rastlanıldı (5 Rhinovirüs, 1 Respiratuvar Sinsitiyal Virüs)

B. pertussis için PZR testi pozitif olan hastalar B. pertussis için PZR testi negatif olan hastalar ve nazofaringeal sürüntü örneği alınmamış hastaların klinik verileri karşılaşııııldı (Tablo II). Buna göre hastaların yaşları, cinsiyetleri ve ortanca hastanede yatış süreleri açısından 3 grup arasında fark saptanmadı (Tablo II). Boğmaca PZR pozitif grubunun beyaz küre ve lenfosit sayısı diğer iki gruba göre anlamlı olarak daha yüksekti $(p<0.01)$ (Tablo II).

Kliniğimize boğmaca/boğmaca benzeri hastalık tanısı ile yatırlan tüm hastalara klaritromisin ( $15 \mathrm{mg} / \mathrm{kg} / \mathrm{gün} 2 \mathrm{dozda}$ ) ve paroksismal öksürük atakları sırasında veya Pulse Oksimetre

Tablo I: Hastaların demografik ve laboratuvar bulguları.

$$
\mathrm{n}=97
$$

\begin{tabular}{|l|c|}
\hline Hasta yaşı (ay) & $2.0(1.0-3.9)^{\star}$ \\
\hline Beyaz küre sayısı (hücre/mm $)$ & $11600(3700-63200)^{*}$ \\
\hline Lenfosit sayısı (hücre/mm³ & $6300(1800-39000)^{*}$ \\
\hline Hastanede yatış süresi (gün) & $4(2-48)^{\star}$ \\
\hline
\end{tabular}

*Ortanca (minimum-maksimum) 
Tablo II: Boğmaca PZR pozitif, boğmaca PZR negatif ve nazofaringeal sürüntü örneği gönderilmemiş hastaların demografik ve laboratuvar bulguları.

\begin{tabular}{|c|c|c|c|c|}
\hline & $\begin{array}{c}\text { Boğmaca PZR } \\
\text { pozitif } \\
(n=12)\end{array}$ & $\begin{array}{c}\text { Boğmaca PZR } \\
\text { negatif } \\
(n=19)\end{array}$ & $\begin{array}{l}\text { Nazofaringeal sürüntü } \\
\text { örneği gönderilmemiş } \\
(\mathrm{n}=66)\end{array}$ & $\mathbf{p}$ \\
\hline $\begin{array}{l}\text { Cinsiyet } \\
\text { (erkek/kadın) }\end{array}$ & $6 / 6$ & $9 / 10$ & $36 / 30$ & 0.82 \\
\hline Hasta yaşı (ay) & $1.8(1.1-3.1)^{\star}$ & $1.8(1.2-3.2)^{*}$ & $2.0(1.0-3.9)^{\star}$ & 0.91 \\
\hline Beyaz küre sayısı (hücre/mm³) & $\begin{array}{c}15375 \\
(11700-63200)^{\star}\end{array}$ & $\begin{array}{c}10230 \\
(4900-27000)^{*}\end{array}$ & $\begin{array}{c}11050 \\
(3700-25710)^{\star}\end{array}$ & $<0.01$ \\
\hline Lenfosit sayısı (hücre/mm³) & $\begin{array}{c}10590 \\
(4980-39000)^{\star}\end{array}$ & $\begin{array}{c}6590 \\
(1800-20400)^{\star}\end{array}$ & $\begin{array}{c}5650 \\
(2000-18300)^{\star}\end{array}$ & $<0.01$ \\
\hline Hastanede yatış süresi (gün) & $5(3-48)^{\star}$ & $4(2-8)^{\star}$ & $4(2-10)^{\star}$ & 0.87 \\
\hline
\end{tabular}

*Ortanca (minimum-maksimum)

Tablo III: Yoğun bakıma devir edilen iki olgunun klinik ve laboratuvar bulguları.

\begin{tabular}{|c|c|c|c|c|c|c|c|c|c|c|}
\hline & 悐 & 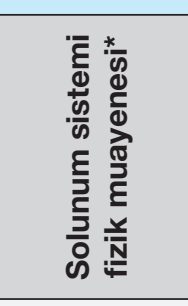 & 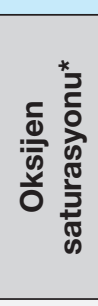 & 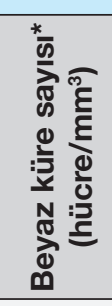 & 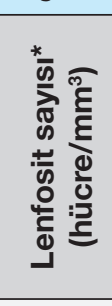 & 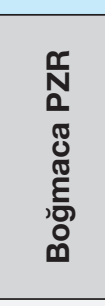 & 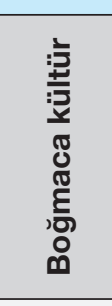 & 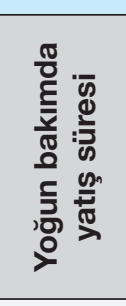 & 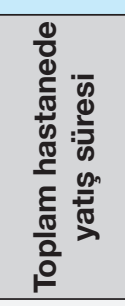 & 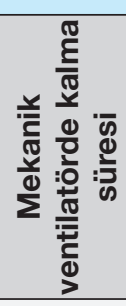 \\
\hline Olgu 1 & 1.5 ay, kız & $\begin{array}{c}\text { Akciğerlerde } \\
\text { yaygın ral }\end{array}$ & $\% 92$ & 63200 & 39000 & Pozitif & Pozitif & 21 gün & 48 gün & 14 gün \\
\hline Olgu 2 & 2.3 ay, erkek & Apne & $\% 98$ & 28700 & 16700 & Pozitif & Pozitif & 7 gün & 14 gün & 4 gün \\
\hline
\end{tabular}

*başvuru sırasındaki

ile ölçülen oksijen saturasyon değerleri <\%94 olduğunda oksijenizasyon tedavisi başlandı. Miks etyoloji düşünülen 47 hastaya klaritromisine ek olarak amoksisilin-klavunat (60-90 mg/ $\mathrm{kg} / \mathrm{gün} 3 \mathrm{dozda}$ ( $\mathrm{n}=37$ ) ve sulbaktam-ampisilin (200mg/kg/gün 4 dozda) ( $n=10)$ tedavileri de verildi. Hastaların 54 tanesi yașları henüz 2 aya ulaşmadığı için aşısızdı, 43 tanesi ise boğmacaya karşı 1 kez aşılanmıștı. Așısız olan hastaların ortalama yaşları $1.6 \pm 0.3$ ay; tek doz aşlı olanların ise $2.7 \pm 0.5$ aydı $(p<0.001)$

Annelerinde de yoğun öksürük şikâyeti bulunan iki olgu servise yatışlarının 10. ve 14. saatinde yoğun bakıma devir edildi. Bu 2 olgunun klinik özellikleri Tablo III'de gösterilmiştir.

\section{TARTIŞMA}

Bu çalışmada, yaşları 4 ayın altında olan, boğmaca/ boğmaca benzeri hastalık tanısı ile izlenen 97 hastanın klinik verileri sunuldu. Hastalarımızın iki tanesinin yoğun bakımda takip edilmesi ve invazif mekanik ventilatör desteği alması boğmacanın bu yaş grubunda önemli morbidite nedeni olduğunu göstermektedir. Hastalı̆ın tanısı klinik ve laboratuvar tanımlama ile konulur. Bu çalışmada boğmaca tanısı DSÖ'nün tanı kriterlerine göre konuldu. Çalıșmamızda hastaların \%32'sinden nazofaringeal sürüntü örneği gönderilmiştir.
Nazofaringeal sürüntü örneklerinden $B$. pertussis için kültür ve B. pertussis PZR çalışlabilmektedir. Kültür yöntemi tanıda altın standarttır (7). Ancak semptomların süresi, antibiyotik kullanımı örnek alım ve taşıma koşulları kültürün duyarlıığını etkiler. Mikroorganizma en sık kataral ve erken paroksismal evrede izole edilebilir. Antibiyotik kullanımı ise yalancı negatifliklere neden olur. PZR testi ise antibiyotik kullanımından ve hastalığın süresinden etkilenmemektedir. Ayrıca kültüre göre çok daha hızlı sonuç alınmaktadır (8). Boğmaca kültür besi yeri teminiyle ilgili sorunlar ve hastaneye bașvuru öncesi hastaların antibiyotik kullanması nedeniyle tüm hasta grubumuzdan boğmaca için örnek alınamadı. Çalışmamızda boğmaca PZR pozitif olan 12 olgunun 7 'sinde $B$. pertussis etkeni üretilebilmiștir. Karlı ve ark. (9) 40 olguluk serilerinde tüm hastalardan boğmaca kültürü gönderilmiş, 4 (\%10) olguda etken saptanmıştır. Hançerli-Törün ve ark. (10) ise boğmaca ön tanısı ile yatırdıkları 26 hastanın hepsinden nazofaringeal sürüntü örneği göndermiş, 12 hastada (\%46) ise boğmaca PZR pozitifliği saptamıştır. Boğmaca benzeri hastalığa neden olan birçok etken vardır. Bordatella holmesii, Bordotella parapertussis, Mycoplasma, Klamidya, Parainfluenza ve Influenza virusları, Enteroviruslar, Respiratuvar Sinsitiyal Virüs ve Adenovirus enfeksiyonları bunlardan en önemlileridir (11). B. pertussis için etken saptanamayan hastalarda da tedavi yaklaşımı benzerdir. Tedavide amaç ataklar sırasında oksijenizasyonun sağlanması, beslenmenin sürdürülmesi ve 
komplikasyonların önlenmesidir. Boğmaca hastalığında yüksek mortalite için risk faktörleri yüksek beyaz küre sayısı, ağır pulmoner hipertansiyon, 6 aylıktan küçük olmak, prematürelik ve tam aşılanmamış olmaktır (12). Bizim çalışmamızda da B. pertussis için PZR pozitif saptanan grubun beyaz küre ve lenfosit sayısı diğer 2 gruba göre anlamlı derecede daha yüksek bulundu. Yoğun bakımda takip edilen bir hastamızın beyaz küre sayısı ise $63200 / \mathrm{mm}^{3}$ tü. Boğmaca toksini hücresel sinyalizasyonu etkilemekte ve lökositoza neden olmaktadır (13). Așırı lökositoz, refrakter pulmoner hipertansiyona ve bozulmuş mikrosirkulasyona neden olmakta bu da organ yetmezliklerine yol açmaktadır $(13,14)$. Post-mortem çalışmalar bu hastaların akciğerlerinde lökosit dolu pulmoner kan damarları ve nektotizan bronşitisin olduğunu göstermiştir $(15,16)$. Literatürde aşıı lökositozu olan kritik hastalarda kan değişimi, plazmaferez ve lökodeplesyon yöntemleriyle löksositozun azaltımasının sağ kalıma olumlu yönde katkı yaptığı ile ilgili çalışmalar mevcuttur (17).

Hastalı̆ı geçirmek ya da aşılama, boğmacaya karşı ömür boyu süren bağışıklık yaratmaz. Aşılama sonrasında koruyuculuk 3-5 yilda azalmaya başlar ve 12 ylla kadar tamamen kaybolur (7). Bu nedenle tüm yaş gruplarında hastalık gelişir. Tüm yaş gruplarında hastalık gelişmekle birlikte 3 ay altı bebeklerde boğmaca yüksek morbidite ve mortaliteye sahiptir. Bebekte boğmacaya spesifik Immünoglobulin G (IgG) düzeyi doğumdan hemen sonra hızla düşmekte, 2. ayın sonunda ise yok denecek kadar azalmaktadır $(18,19)$. Bu nedenle risk altındaki bu bebekleri boğmacadan korumak için yeni koruma stratejileri geliştirilmelidir. Bunlardan en önemlisi koza stratejisi ile kombine şekilde anneyi gebe iken aşllamaktır $(19,20)$.

Klinik olarak boğmaca/boğmaca benzeri hastalık tanısı konulan 97 hastanın verilerini sunduğumuz bu çalışmamızın kısıt|lıkları; retrospektif olması, örneklem büyüklüğümüzün kısmen küçük olması ve tüm hastalardan örnek gönderilememiş olmasıdır.

Sonuç olarak; çalıșmamızın bulguları boğmaca enfeksiyonunun erken bebeklik döneminde önemli morbidite ve mortalite nedeni olduğunu göstermiştir. Bu bebekleri korumak için yeni stratejiler geliştirilmelidir.

\section{KAYNAKLAR}

1. Organization WHO. Global Vaccine Action Plan. Monitoring, evaluation \& accountability. Secretariat annual report 2015. Geneva: World Health Organization 2015.

2. Ulloa-Gutierrez R, Boza R, Carvajal-Riggioni D, Baltodano A. Pertussis: should we improve intensive care management or vaccination strategies? Expert Rev Vaccines 2011;10:49-53.

3. Cortese MM, Baughman AL, Zhang R, Srivastava PU, Wallace GS. Pertussis hospitalizations among infants in the United States, 1993 to 2004. Pediatrics 2008;121:484-92.

4. Surridge J, Segedin ER, Grant CC. Pertussis requiring intensive care. Arch Dis Child 2007; 92:970-75.
5. Winter K, Harriman K, Zipprich J, Schechter R, Talarico J, Walt J et al. California pertussis epidemic, 2010. J Pediatr 2012;161:10916.

6. Cherry JD, Grimprel E, Guiso N, Heininger U, Mertsola J. Defining pertussis epidemiology: clinical, microbiologic and serologic perspectives. Pediatr Infect Dis J 2005;24:S25-34.

7. Wood N, Mclntyre P. Pertussis: review of epidemiology, diagnosis, management and prevention. Paediatr Respir Rev 2008;9:201-12.

8. Otar G, Kılıç A, Yıldız I, Varkal MA, Devecioğlu E. Boğmaca Enfeksiyonunun Tanı ve Tedavisi. Cocuk Dergisi 2014;14:100-7.

9. Karlı A, Şensoy G, Belet N, Yener N, Akgün M, Paksu MŞ. Boğmaca Nedeni ile Hastaneye Yatan Süt Çocuklarında Klinik Tablo ve Prognoz. J Pediatr Inf 2013;7:47-52.

10. Törün SH, Çalişkan BB, Salman N, Öksüz L, Somer A, Gürler N. Kliniğimizde 2010 Kıș-Sonbahar-Yaz Döneminde Yatırılarak İzlenmiș Boğmaca Vakalarının Sunumu. Cocuk Dergisi 2010;10:133-8.

11. Long SS. Pertussis (Bordetella pertussis and Bordetella parapertussis). In: Kliegman BF, Stanton BF, St Geme JW, Schor NF (eds). Nelson Textbook Of Pediatrics 20th ed. Philadelphia, Elsevier 2016: 1377-82.

12. Oikonomakou M. Exchange Transfusion: An Extra Therapeutic Tool for Severe Pertussis. EC Paediatrics 2018;7:878-83.

13. Straney L, Schibler A, Ganeshalingham A, Alexander J, Festa M, Slater A, et al. Burden and outcomes of severe pertussis infection in critically ill infants. Pediatr Crit Care Med 2016; 17:735-42.

14. Goulin GD, Kaya KM, Bradley JS. Severe pulmonary hypertension associated with shock and death in infants infected with Bordetella pertussis. Crit Care Med 1993; 21:1791-4.

15. Paddock CD, Sanden GN, Cherry JD, Gal AA, Langston C, Tatti $\mathrm{KM}$, et al. Pathology and pathogenesis of fatal Bordetella pertussis infection in infants. Clin Infect Dis 2008; 47:328-38.

16. Sawal M, Cohen M, Irazuzta JE, Kumar R, Kirton C, Brundler MA, et al. Fulminant pertussis: A multi-center study with new insights into the clinico-pathological mechanisms. Pediatr Pulmonol 2009;44:970-80.

17. Rowlands HE, Goldman AP, Harrington K, Karimova A, Brierly J, Cross $\mathrm{N}$, et al. Impact of rapid leukodepletion on the outcome of severe clinical pertussis in young infants. Pediatrics 2010;126:e81627.

18. Carrico CA, O'keefe C. Protecting infants against pertussis: The cocooning strategy in practice. Nurse Pract 2013;38:40-5.

19. Terzi H, Kitiş Y. Boğmaca Bağışıklamasında Farklı Bir Yaklaşım: Koza Stratejisi. Turkiye Klinikleri Hemşirelik Bilimleri 2018;10:88-94.

20. Akçaboy M, Oğuz MM, Altınel EA, Yüksel D, Şenel S, Zorlu P. Komplikasyonlarla Seyreden Bir Boğmaca Olgusu Nedeniyle "Koza Stratejisi". GMJ 2017;28:48-50. 